\title{
Association between Vaginal Micro-environment Disorder and Cervical Intraepithelial Neoplasia in a Community Based Population in China
}

\author{
$\mathrm{Li} \mathrm{Li}^{{ }^{*}}$, Ling Ding1 ${ }^{*}$, Tao Gao ${ }^{2}$, Yuanjing Lyu ${ }^{1}$, Ming Wang ${ }^{1}$, Li Song ${ }^{1}$, Xiaoxue Li ${ }^{1}$, Wen Gao ${ }^{1}$, Yang Han ${ }^{1}$, \\ Haixia Jia ${ }^{1}$, Jintao Wang ${ }^{1 凶}$ \\ 1. Department of Epidemiology, School of Public Health, Shanxi Medical University, Taiyuan, China. \\ 2. Department of Preventive Medicine, Robert H. Lurie Comprehensive Cancer Center, Feinberg School of Medicine, Northwestern University, Chicago 60611, \\ USA. \\ * These authors contributed equally to this work. \\ $\triangle$ Corresponding author: Jintao Wang, MD. Department of Epidemiology, School of Public Health, Shanxi Medical University, 56, Xinjian Nan Road, Taiyuan, \\ China. Tel +86 03514135245. Email address: wangit59@163.com
}

(1) The author(s). This is an open access article distributed under the terms of the Creative Commons Attribution License (https://creativecommons.org/licenses/by/4.0/). See http://ivyspring.com/terms for full terms and conditions.

Received: 2019.03.19; Accepted: 2019.08.31; Published: 2020.01.01

\begin{abstract}
There are other factors that contribute to cervical carcinogenesis except HPV infection. This study aimed to investigate the association between vaginal micro-environment factors, including $\mathrm{H}_{2} \mathrm{O}_{2}$, vaginal $\mathrm{PH}$ value, vagina cleanness, $\beta$-glucuronidase, coagulase, neuraminidase and leukocyte esterase and cervical intraeipithelial neoplasia (CIN). In total 1019 participants, including 623 normal cervical (NC) women, 303 patients with low-grade cervical intraepithelial neoplasia (CINI) and 93 patients with high-grade cervical intraepithelial neoplasia (CIN2/3), were enrolled into the study. HPV genotyping was detected by flow-through hybridization and gene chip. Vaginal $\mathrm{H}_{2} \mathrm{O}_{2}$, $\beta$-glucuronidase, coagulase, neuraminidase and leukocyte esterase were detected by Aerobic Vaginitis (AV) / Bacterial Vaginal Disease (BV) Five Joint Test Kit. Vaginal PH was measured on the glass slide after microscopy, using color strips with a PH range of 3.8-5.4. Vagina cleanness was determined according to the National Clinical Laboratory Practice Guideline. $X^{2}$ test and Logistic regression were operated using SPSS 22.0 software. Our results showed that HPV16 infection rate and the abnormal rates of $\mathrm{H}_{2} \mathrm{O}_{2}, \mathrm{PH}$, vagina cleanness, $\beta$-glucuronidase or neuraminidase increased gradually along with the severity of $\mathrm{CIN}(P<0.05)$. Abnormities of $\mathrm{H}_{2} \mathrm{O}_{2}$, cleanness, $\beta$-glucuronidase and neuraminidase were risk factors for CIN regardless of HPVI6 infection, furthermore, abnormities of $\mathrm{PH}$ value, leukocyte esterase could also increase the risk of CIN in HPV16 positive group. In addition, women with abnormal vaginal micro-environment factors in HPV16 positive group had a significantly higher risk of developing CIN than HPV16 negative group. The results from generalized multifactor dimensionality reduction (GMDR) model showed that there was interaction effect with abnormities of vagina cleanness, $\mathrm{H}_{2} \mathrm{O}_{2}, \beta$-glucuronidase and neuraminidase on $\mathrm{CIN} 2 / 3$ in HPV16 negative group, while, there was interaction effect with abnormities of vagina cleanness, $\beta$-glucuronidase and neuraminidase on $\mathrm{CINI}$ and with abnormities of vagina cleanness, $\mathrm{PH}, \mathrm{H}_{2} \mathrm{O}_{2}$, $\beta$-glucuronidase, neuraminidase and leukocyte esterase on CIN2/3 in HPV16 positive group. Our results suggested that vaginal micro-environment disorder could increase the risk of $\mathrm{CIN}$, especially, the abnormality of $\mathrm{H}_{2} \mathrm{O}_{2}$, cleanness, $\beta$-glucuronidase and neuraminidase. There were interaction effects with abnormities of $\mathrm{H}_{2} \mathrm{O}_{2}$, vagina cleanness, $\beta$-glucuronidase and neuraminidase on $\mathrm{CIN}$ whether HPV16 was infected or not.
\end{abstract}

Key words: cervical intraepithelial neoplasia, HPV16, vaginal micro-environment factors 


\section{Introduction}

Cervical cancer is one of the most common gynecological malignancies worldwide with an estimated 570,000 cases and 311,000 deaths in 2018 [1]. The causal role of high-risk human papillomavirus (HR-HPV) in cervical intraepithelial neoplasia (CIN) has been approved by various studies [2, 3]. Especially, HPV16 is by far the most common type of carcinogenic globally, with the positivity rate of over $60 \%$ in cervical cancer patients [4]. The majority of HPV infections are transient with subclinical or asymptomatic appearance $[5,6]$, only a small proportion of women infected with the virus develop clinically significant pre-invasive lesions and cervical cancer. As a precancerous lesion of cervical cancer, it takes an average of 8 years for CIN to develop into cervical cancer. Therefore, it is of great significance to explore the main risk factors of CIN for blocking the occurrence of cervical cancer.

In recent years, the researches on cancer or chronic disease focused on the relationship between intestinal micro-ecology $[7,8]$ and oral micro-ecology [9]. The association between vaginal micro-ecology and cervical cancer had also been concerned. But there is no clear definition of guiding vaginal micro-environment disorder up to now. Vaginal $\mathrm{PH}$ value, $\mathrm{H}_{2} \mathrm{O}_{2}$, vagina cleanness, $\beta$-glucuronidase, coagulase, neuraminidase and leukocyte esterase are important evaluation index to evaluate the vaginal micro-ecology in clinical practice [10, 11], which could comprehensively reflect vaginal micro-ecology from vaginal acidity and alkalinity, Lactobacillus function, microbial metabolites and inflammatory reaction, therefore, they are generally referred as vaginal micro-environmental factors. It was reported that increased vaginal $\mathrm{PH}$ could increase the risk of HPV infection by $30 \%$ [12]. $\mathrm{H}_{2} \mathrm{O}_{2}$ can catalyze peroxidase to produce hypochlorite, which can prevent HPV virus from colonizing and growing in cervical epithelial cells [13]. Poor cleanness may be related to bacterial vaginitis [14] and aerobic vaginitis [15]. A case-control study found that neuraminidase abnormal rate was significantly higher in patients with bacterial vaginitis than in non-patients [16]. Leukocyte esterase activity in patients with recurrent vaginal candidiasis and bacterial vaginitis was higher than that in normal women [17]. Although these studies suggest that vaginal micro-environment factors may plays an important role in HPV infection and bacterial vaginitis, it is not clear about the potential function of vaginal micro-environment factors on CIN progression. This study aimed to explore the association between vaginal micro-environment factors and CIN in regard of HPV16 infection so as to provide new ideas for the further study of CIN.

\section{Materials and Methods}

\section{Study population}

1019 participants were enrolled in the current study, including 623 participants with NC, 303 with CIN1, and 93 with CIN2/3. These participants came from the community cohort which was established during June 2014 to September 2014 and included around 20000 women in Jiexiu, Shanxi, China. The participants were considered eligible according to the following inclusion criteria: married, aged 18-65 years, Han ethnicity, and resided in Jiexiu for at least 1 year and the exclusion criteria included the following: washed vulva within 48 hours, had sexual intercourse or used drug in vagina within the last 3 days, used of antibiotics within one month. A cytobrush was used in the gynecological examination to collect exfoliative cells for TCT (Thinprep Cytologic Test) detection. Total 19593 women in the cohort completed TCT detection and 1074 women of them were diagnosed as atypical squamous cells of undetermined significance (ASC-US) and above. Among them, 44 women who refused to undergo colposcope and histopathologic examination and 11 women with cervical squamous cell carcinoma (SCC) were excluded (Fig.1). Informed consent was obtained from all individual participants and the study was approved by Shanxi Medical University Science Research Ethics Committee.

\section{Sample collection}

Information about participants' sociodemographic characteristics, vaginal hygiene, history of gynecological disease, family history of cancer was collected using structured questionnaire. Cervical exfoliative cells were collected for HPV detection. Sterile cotton swab was used to collect secretions on the posterior fornix of vagina, and then put into a soft

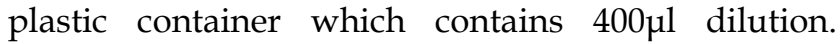
Cervical tissues were collected using colposcopy directed biopsy for pathological test.

\section{HPV 16 detection}

The exfoliative cells were centrifuged for $15 \mathrm{~min}$ at $4^{\circ} \mathrm{C}, 13000 \mathrm{rpm}$. Then HPV-DNA was extracted using DNA extraction kit (Hybribio, China). PCR-based flow-through hybridization and gene chip system (Hybribio, China) was used for HPV genotyping. This genotyping test could qualitatively detect 15 high-risk types: HPV16, 18, 31, 33, 35, 39, 45, 51, 52, 53, 56, 58, 59, 66, 68 and 6 low-risk types: HPV6, 11, 42, 43, 44, CP8304. Single or mixed HPV16 infection was defined as HPV16 infections in this study. 


\section{Detection of vaginal $\mathrm{PH}$ and vagina cleanness}

Vaginal PH value was measured using color strips with a $\mathrm{PH}$ range of 3.8-5.4. It was normal if $\mathrm{PH}$ was no more than $4.5(\mathrm{PH} \leq 4.5)$ and abnormal if $\mathrm{PH}>$ 4.5. Vagina cleanness was judged strictly according to the National Clinical Laboratory Practice Guideline [18] standard: I II was defined as normal, and III IV as abnormal.

\section{Detection of bacterial enzymes in vagina}

In accordance with the operation instructions of the Aerobic Vaginitis (AV) / Bacterial Vaginal Disease (BV) Five Joint Test Kit (Beijing ZhongSheng JinYu Diagnosis Technology Co, Ltd., Beijing, China.), a drop of sample (about $35 \mathrm{ml}$ ) was added into each well. After incubating the mixture for 10 minutes at $37^{\circ} \mathrm{C}$, a drop of color development solution A and B were added to the neuraminidase well and the coagulase well respectively. According to the

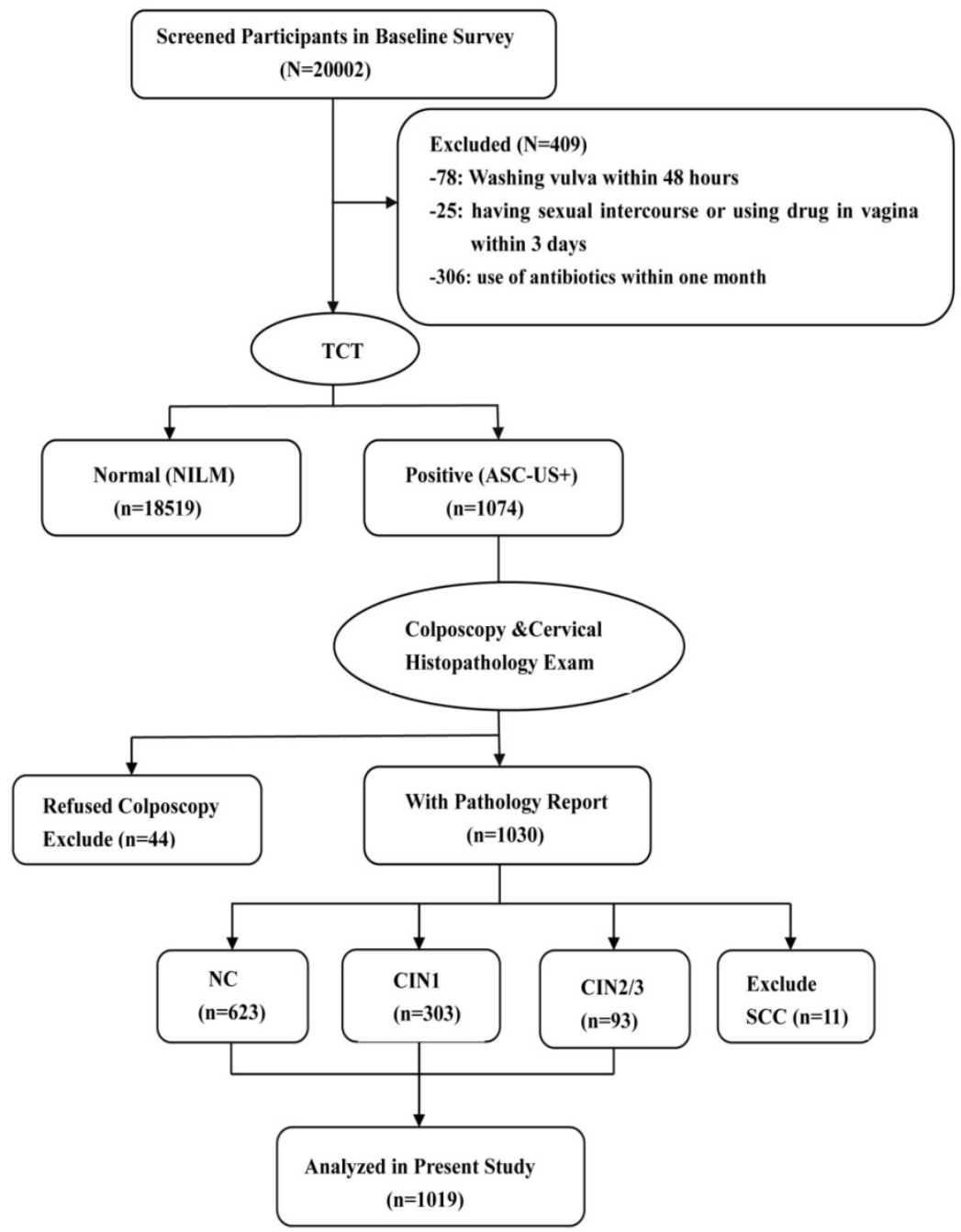

Figure 1. Flow chart of participant screening in the study. TCT, Thinprep Cytologic Test. ASC-US+, atypical squamous cells of undetermined significance or above. NILM, negative for intraepithelial lesion or malignancy. CIN, cervical intraepithelial neoplasia. technicians' instruction, the results were interpreted. In this study, negative results were defined as normal and positive results as abnormal. Besides, the standard quality control products in the kit were used for quality control testing of each indicator to ensure the accuracy of the experimental results.

\section{Definition of vaginal micro-environment disorder}

Currently, there is no clear definition of guiding vaginal micro-environment disorder. In our study, it was defined as any of the above vaginal micro-environment factors abnormalities, including vaginal $\mathrm{PH}$ value, $\mathrm{H}_{2} \mathrm{O}_{2}$, vagina cleanness, $\beta$-glucuronidase, coagulase, neuraminidase and leukocyte esterase, which are important biomarkers for evaluating vaginal micro-ecology in clinical practice $[10,11]$.

\section{Statistical analyses}

Data analyses were performed with SPSS 22.0 statistical software. Count data were examined by Chi-square and trend Chi-square tests. Multinomial logistic regression model was used to estimate odds ratio $(O R)$. And the interaction among multiple factors was analyzed by generalized multifactor dimensionality reduction (GMDR). Statistical significance was set at $a=0.05$.

\section{Results}

\section{Socio-demographic characteristics and relevant factors}

Our study showed that there were significant differences on occupation, passive smoking, frequency of vulva cleaning, frequency of underwear washing, washing vulva after sexual intercourse and contraception history between NC group, CIN1 group and CIN2/3 group (Table 1). There were no significant differences on age, education, marital status, age at menarche, gynecological history, numbers of pregnancy et al among the three groups $(P>0.05)$.

\section{Related factors of cervical lesions}

The first three principal components are selected since their eigenvalues are greater than 1 (Table 2). The latent variable FAC1 represented frequency of vulva cleaning and frequency of underwear washing. Latent variable 
FAC2 represented washing vulva after sexual intercourse and occupation. Latent variable FAC3 represented passive smoking and contraception history. Partial correlation KMO (Kaiser-MeyerOlkin) is 0.658 , which was suitable for factor analysis (Table 3).

\section{Association between HPV16 and CIN}

HPV16 infection rates in women with CIN1 (21.1\%) and CIN2/3 (44.1\%) were significantly higher than women with NC (12.0\%). The probability of HPV16 positive individuals to develop CIN1 and CIN2/3 were respectively 1.97 and 5.71 times than HPV16 negative ones. With the progression of CIN, the infection rate of HPV16 $\left(\chi^{2}\right.$ trend $\left.=55.45, P<0.001\right)$ increased gradually (Fig.2).

\section{Association between vaginal micro-environment factors and CIN}

There were significant differences in the abnormal rates of $\mathrm{H}_{2} \mathrm{O}_{2}\left(\chi^{2}=26.60, P<0.001\right)$, vagina cleanness $\quad\left(X^{2}=21.02, \quad P<0.001\right), \quad \beta$-glucuronidase $\left(\chi^{2}=17.88, P<0.001\right)$, coagulase $\left(\chi^{2}=7.61, P=0.022\right)$ and neuraminidase $\left(\chi^{2}=15.21, P<0.001\right)$ in the groups of $\mathrm{NC}, \mathrm{CIN} 1, \mathrm{CIN} 2 / 3$. The abnormal rates of $\mathrm{H}_{2} \mathrm{O}_{2}$, $\beta$-glucuronidase, neuraminidase and leukocyte esterase in CIN1 group were significantly higher than that in $\mathrm{NC}$ group, while the abnormal rates of $\mathrm{H}_{2} \mathrm{O}_{2}$, vagina cleanness, $\beta$-glucuronidase and neuraminidase in CIN2/3 group were significantly higher than in NC group. We found that the abnormal rates of $\mathrm{H}_{2} \mathrm{O}_{2}, \mathrm{PH}$, vagina cleanness, $\beta$-glucuronidase and neuraminidase were gradually increased with the severity of cervical lesions $(P<0.05)$, showing in Fig.3.

\section{Association between vaginal micro-environment factors and $\mathrm{CIN}$ in different HPV 16 infection state}

In the HPV16 negative group, $\mathrm{H}_{2} \mathrm{O}_{2}$, cleanness, $\beta$-glucuronidase and neuraminidase abnormities were risk factors for $\mathrm{CIN} 2 / 3$, and the abnormal rates increased with the severity of cervical lesions (Table 4). Among women with HPV16 infection, there were significant differences between the three groups in abnormal rates of $\mathrm{H}_{2} \mathrm{O}_{2}, \mathrm{PH}$, cleanness, $\beta$-glucuronidase, coagulase, neuraminidase and leukocyte esterase, meanwhile, we observed that $\mathrm{H}_{2} \mathrm{O}_{2}$, cleanness, $\beta$-glucuronidase and neuraminidase abnormities were collective risk factors both in CIN1 and CIN2/3 group and abnormal $\mathrm{PH}$ and leukocyte esterase were also risk factors for CIN2/3 (Table 4). In addition, women with abnormal vaginal microenvironment factors in HPV16 positive group had a significantly higher risk on CIN than in HPV16 negative group (Table 4 and Fig.4).
Table 1. Socio-demographic characteristics and related factors among cervical lesion groups

\begin{tabular}{|c|c|c|c|c|}
\hline Variables & NC & CIN1 & CIN2/3 & $P$-value \\
\hline Occupation & & & & 0.041 \\
\hline Peasant & $156(25.0)$ & $93(30.7)$ & $33(35.5)$ & \\
\hline Others & $467(75.0)$ & $210(69.3)$ & $60(64.5)$ & \\
\hline Passive smoking & & & & 0.001 \\
\hline Yes & $360(57.8)$ & $212(70.0)$ & $63(67.7)$ & \\
\hline No & $263(42.2)$ & $91(30.0)$ & $30(32.3)$ & \\
\hline Frequency of vulva cleaning & & & & 0.032 \\
\hline$\leq 1$ time/month & $20(3.2)$ & $19(6.3)$ & $9(9.7)$ & \\
\hline 3 times/week-1 time/month & $263(42.2)$ & $118(38.9)$ & $39(41.9)$ & \\
\hline$\geq 3$ times/week & $340(54.6)$ & $166(54.8)$ & $45(48.4)$ & \\
\hline \multicolumn{4}{|c|}{ Frequency of underwear washing } & 0.003 \\
\hline$\leq 1$ time/month & 10(1.6) & $10(3.3)$ & $8(8.6)$ & \\
\hline 3 times/week-1 time/month & $240(38.5)$ & $108(35.6)$ & $29(31.2)$ & \\
\hline$\geq 3$ times/week & $373(59.9)$ & 185(61.1) & $56(60.2)$ & \\
\hline \multicolumn{4}{|c|}{ Washing vulva after sexual intercourse } & 0.027 \\
\hline Yes & $470(75.4)$ & $250(82.5)$ & $77(83.8)$ & \\
\hline No & $153(24.6)$ & $53(17.5)$ & $16(17.2)$ & \\
\hline Contraception history & & & & 0.023 \\
\hline Yes & $549(88.1)$ & 276(91.1) & $75(80.6)$ & \\
\hline No & 74(11.9) & $27(8.9)$ & 18(19.4) & \\
\hline
\end{tabular}

Table 2. Eigenvalues of the related matrices

\begin{tabular}{llll}
\hline Component & Eigenvalues & $\begin{array}{l}\text { Contribution } \\
\text { rate } \mathbf{( \% )}\end{array}$ & $\begin{array}{l}\text { Cumulative } \\
\text { contribution rate (\%) }\end{array}$ \\
\hline 1 & 1.479 & 26.467 & 24.647 \\
2 & 1.126 & 18.771 & 43.418 \\
3 & 1.049 & 17.478 & 60.897 \\
4 & 0.966 & 16.094 & 76.991 \\
5 & 0.838 & 13.959 & 90.949 \\
6 & 0.543 & 9.051 & 100.00 \\
\hline
\end{tabular}

Table 3. Orthogonal rotation of the factor load

\begin{tabular}{llll}
\hline Factors & FAC1 & FAC2 & FAC3 \\
\hline Occupation & -0.083 & $0.740^{*}$ & 0.249 \\
Passive smoking & 0.096 & -0.034 & $0.839^{*}$ \\
Frequency of vulva cleaning & $0.849^{*}$ & -0.008 & 0.109 \\
Frequency of underwear washing & $0.816^{*}$ & 0.071 & -0.200 \\
Washing the vulva after & -0.142 & $-0.751^{*}$ & 0.196 \\
sexual intercourse & & & \\
Contraception history & -0.112 & 0.046 & $0.492^{*}$ \\
\hline
\end{tabular}

* Factors corresponding to latent variables (FAC1, FAC2, FAC3).

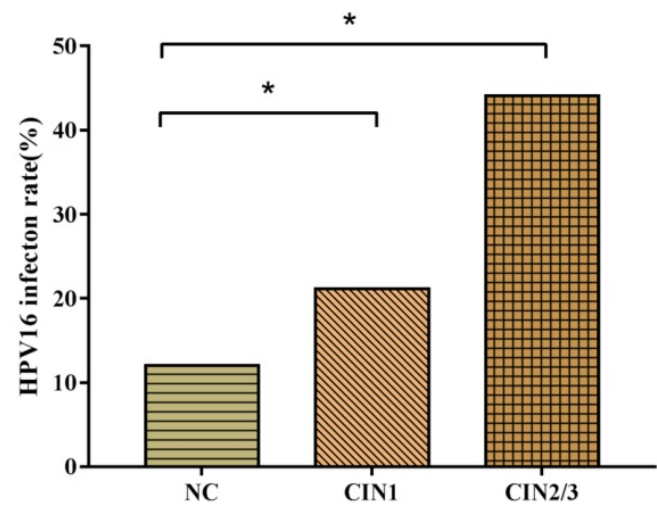

Figure 2. HPV16 infection rates in CIN. HPV16 infection rates ascended with the progression of cervical lesions $\left(\chi^{2}\right.$ trend $\left.=55.45, P<0.001\right)$. $*$ There was a statistical difference in comparison to NC group adjusted by FAC1, FAC2 and FAC3 $(P<0.05)$. 


\section{Interaction between vaginal micro-environ- ment factors in CIN according to HPV 16 infection}

In the HPV16 negative group, there was interaction effect with abnormities of $\mathrm{H}_{2} \mathrm{O}_{2}$, vagina cleanness, $\beta$-glucuronidase and neuraminidase on CIN2/3. In the HPV16 positive group, there was interaction effect with abnormities of vagina cleanness, $\beta$-glucuronidase and neuraminidase on CIN1 and with abnormities of vagina cleanness, $\mathrm{PH}$, $\mathrm{H}_{2} \mathrm{O}_{2}, \beta$-glucuronidase, neuraminidase and leukocyte esterase on CIN2/3 (Table 5).

\section{Discussion}

The vaginal micro-environment plays an important role in reproductive health. The vaginal micro-environment disorder is closed to sexually transmitted diseases, bacterial vaginitis, and so on. But there is no clear definition about vaginal micro-environment disorder up to now. Vaginal $\mathrm{PH}$ value, $\mathrm{H}_{2} \mathrm{O}_{2}$, vagina cleanness, $\beta$-glucuronidase, coagulase, neuraminidase and leukocyte esterase, which could comprehensively reflect vaginal micro-ecology from vaginal acidity and alkalinity, Lactobacillus function, microbial metabolites and inflammatory reaction, are generally referred as vaginal micro-environmental factors to evaluate the vaginal micro-ecology in clinical practice $[10,11]$.

Lactobacillus, which is dominant bacteria in vagina, plays an important role in maintaining vaginal microenvironment. Some research showed that Lactobacillus could defend against pathogens and sexually transmitted infections through maintenance of a hostile $\mathrm{PH}$ and production of species metabolites, bacteriocin [19], while increase of $\mathrm{PH}$ value and decrease of $\mathrm{H}_{2} \mathrm{O}_{2}$ in vagina are closely related to the occurrence of vaginitis [20]. Incidence of precancerous lesions increased significantly in individuals with poor vagina cleanness than normal population [21]. In the study, we found that the abnormal rates of $\mathrm{H}_{2} \mathrm{O}_{2}$, $\mathrm{PH}$ and vagina cleanness gradually increased with the severity of cervical neoplasm, and the abnormity of $\mathrm{H}_{2} \mathrm{O}_{2}$, $\mathrm{PH}$ and vagina cleanness could increase the risk of CIN. It suggested that $\mathrm{H}_{2} \mathrm{O}_{2}, \mathrm{PH}$ and vagina cleanness might be used as indicators to predict the progress of CIN.

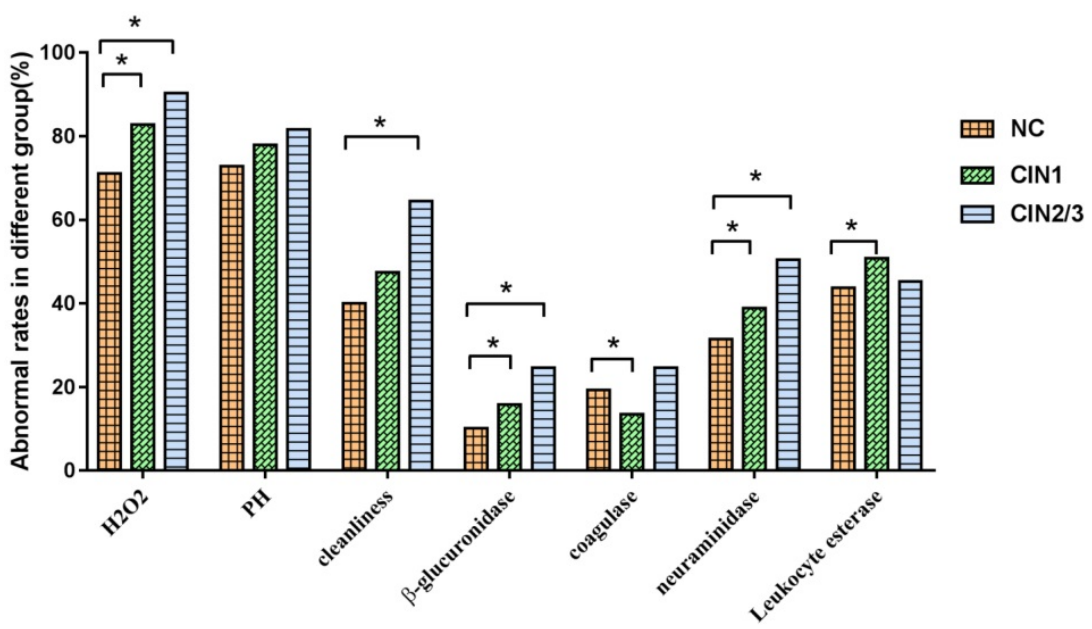

Figure 3. Association between vaginal micro-environment factors and $\mathrm{CIN}$. ${ }^{*}$ There was a statistical difference in comparison to NC group $(P<0.05)$.
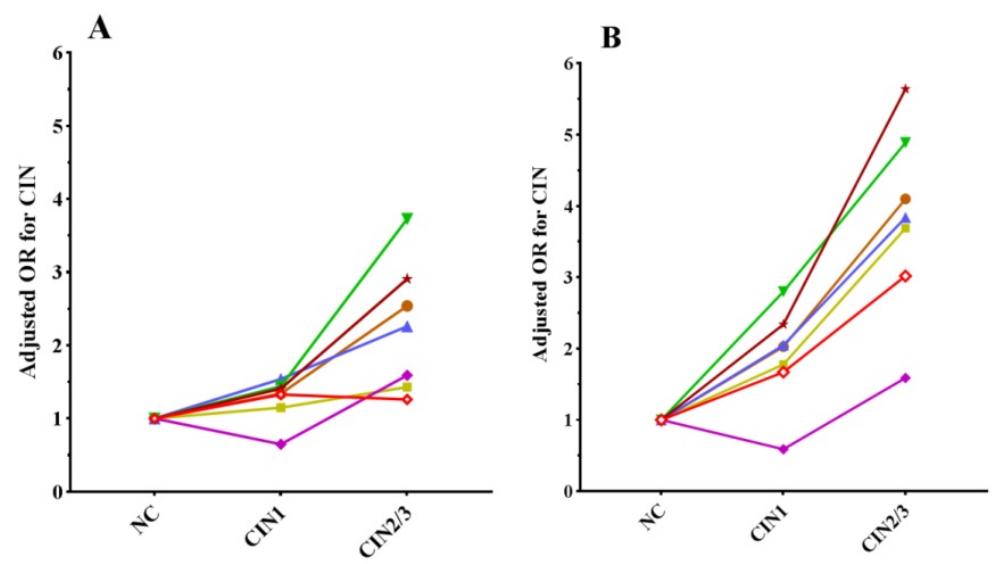

$\rightarrow \mathrm{H}_{2} \mathrm{O}_{2}$

$-\mathrm{PH}$

- Vagina cleaness

* $\beta$-glucuronidase

$\rightarrow$ coagulase

- neuraminidase

$\diamond$ Leukocyte esterase

Figure 4. Trend of OR of vaginal micro-environment factors with the progress of cervical lesions in HPV16 negative group (A) and HPV16 positive group (B). 
Table 4. Association between vaginal micro-environment factors change and CIN in different HPV16 infection groups

\begin{tabular}{|c|c|c|c|c|c|c|}
\hline \multirow[t]{2}{*}{ Factors } & \multicolumn{3}{|c|}{ HPV16 negative group } & \multicolumn{3}{|c|}{ HPV16 positive group } \\
\hline & Group & $\begin{array}{l}\text { Abnormal persons } \\
(\%)\end{array}$ & $a O R^{\#}(95 \% C I)$ & Group & Abnorma & $a O R^{\#}(95 \% C I)$ \\
\hline \multirow[t]{4}{*}{$\mathrm{H}_{2} \mathrm{O}_{2}$} & $\mathrm{NC}$ & $395(72.1)$ & 1.00 & $\mathrm{NC}$ & $57(76.0)$ & 1.00 \\
\hline & CIN1 & $184(77.0)$ & $1.34(0.94-1.92)$ & CIN1 & $56(87.5)$ & 2.03(1.38-2.98) \\
\hline & CIN2/3 & $45(86.5)$ & $2.54(1.12-5.76)$ & CIN2/3 & $38(92.7)$ & $4.10(1.60-10.52)$ \\
\hline & \multicolumn{3}{|c|}{$\chi^{2}=6.41, P=0.041 ; \chi^{2}$ trend $=6.10, P=0.014$} & \multicolumn{3}{|c|}{$X^{2}=6.42, P=0.040 ; \chi^{2}$ trend $=6.09, P=0.014$} \\
\hline \multirow[t]{4}{*}{ PH } & $\mathrm{NC}$ & $396(72.3)$ & 1.00 & $\mathrm{NC}$ & $53(70.7)$ & 1.00 \\
\hline & CIN1 & $179(74.9)$ & $1.15(0.81-1.64)$ & CIN1 & $52(81.3)$ & $1.78(0.79-3.99)$ \\
\hline & $\mathrm{CIN} 2 / 3$ & $41(78.8)$ & $1.43(0.71-2.85)$ & $\mathrm{CIN} 2 / 3$ & $30(90.2)$ & $3.69(1.16-11.74)$ \\
\hline & \multicolumn{3}{|c|}{$X^{2}=1.43, P=0.490 ; \chi^{2}$ trend $=1.40, P=0.236$} & \multicolumn{3}{|c|}{$X^{2}=6.43, P=0.040 ; \chi^{2}$ trend $=6.38, P=0.012$} \\
\hline \multirow[t]{4}{*}{ Vagina cleanness } & $\mathrm{NC}$ & $213(35.9)$ & 1.00 & $\mathrm{NC}$ & $29(38.7)$ & 1.00 \\
\hline & CIN1 & $121(50.6)$ & $1.54(1.13-2.10)$ & CIN1 & $36(56.3)$ & $2.05(1.03-4.05)$ \\
\hline & CIN2/3 & $31(59.6)$ & $2.26(1.26-4.04)$ & CIN2/3 & $29(70.7)$ & $3.84(1.67-8.83)$ \\
\hline & \multicolumn{3}{|c|}{$X^{2}=15.22, P<0.001 ; \chi^{2}$ trend $=15.12, P<0.001$} & \multicolumn{3}{|c|}{$\chi^{2}=11.57, P=0.003 ; \chi^{2}$ trend $=11.47, P=0.00$} \\
\hline \multirow[t]{4}{*}{$\beta$-glucuronidase } & $\mathrm{NC}$ & $61(10.7)$ & 1.00 & $\mathrm{NC}$ & $8(11.1)$ & 1.00 \\
\hline & CIN1 & $38(15.9)$ & $1.44(0.93-2.24)$ & CIN1 & $17(26.6)$ & 2.92(1.15-7.38) \\
\hline & CIN2/3 & $17(32.7)$ & $3.73(1.97-7.08)$ & CIN2/3 & $16(39.0)$ & $4.89(1.83-13.09)$ \\
\hline & \multicolumn{3}{|c|}{$\chi^{2}=19.74, P<0.001 ; \chi^{2}$ trend $=16.51, P<0.001$} & \multicolumn{3}{|c|}{$\chi^{2}=12.93, P=0.002 ; \chi^{2}$ trend $=12.79, P<0.001$} \\
\hline \multirow[t]{4}{*}{ coagulase } & $\mathrm{NC}$ & $104(19.0)$ & 1.00 & $\mathrm{NC}$ & $20(26.7)$ & 1.00 \\
\hline & CIN1 & $33(13.8)$ & $0.65(0.42-1.01)$ & CIN1 & 10(15.6) & $0.51(0.22-1.19)$ \\
\hline & CIN2/3 & $14(26.9)$ & $1.59(0.82-3.06)$ & CIN2/3 & $15(36.6)$ & $1.59(0.70-3.59)$ \\
\hline & \multicolumn{3}{|c|}{$X^{2}=6.00, P=0.050 ; \chi^{2}$ trend $=0.01, P=0.910$} & \multicolumn{3}{|c|}{$\chi^{2}=6.05, P=0.048 ; \chi^{2}$ trend $=0.59, P=0.441$} \\
\hline \multirow[t]{4}{*}{ neuraminidase } & $\mathrm{NC}$ & $125(22.8)$ & 1.00 & $\mathrm{NC}$ & $17(22.7)$ & 1.00 \\
\hline & CIN1 & $72(30.1)$ & $1.41(0.98-1.99)$ & CIN1 & $26(40.6)$ & $2.34(1.11-4.93)$ \\
\hline & CIN2/3 & $24(46.2)$ & $2.91(1.62-5.22)$ & CIN2/3 & $26(63.4)$ & $5.64(2.40-13.25)$ \\
\hline & \multicolumn{3}{|c|}{$X^{2}=15.81, P<0.001 ; \chi^{2}$ trend $=14.75, P<0.001$} & \multicolumn{3}{|c|}{$\chi^{2}=18.84, P<0.001 ; \chi^{2}$ trend $=18.64, P<0.001$} \\
\hline \multirow[t]{4}{*}{ leukocyte esterase } & $\mathrm{NC}$ & $233(42.5)$ & 1.00 & $\mathrm{NC}$ & $29(38.7)$ & 1.00 \\
\hline & CIN1 & $117(49.0)$ & $1.33(0.98-1.82)$ & CIN1 & $33(51.6)$ & $1.67(0.84-3.32)$ \\
\hline & $\mathrm{CIN} 2 / 3$ & $25(48.1)$ & $1.26(0.71-2.23)$ & $\mathrm{CIN} 2 / 3$ & $26(63.4)$ & $3.02(1.33-6.82)$ \\
\hline & \multicolumn{3}{|c|}{$\chi^{2}=3.05, P=0.218 ; \chi^{2}$ trend $=2.47, P=0.116$} & \multicolumn{3}{|c|}{$\chi^{2}=6.78, P=0.034 ; \chi^{2}$ trend $=6.74, P=0.009$} \\
\hline
\end{tabular}

\# Adjusted by FAC1, FAC2 and FAC3

Table 5. Interaction of vaginal micro-environment factors on CIN by GMDR analysis

\begin{tabular}{|c|c|c|c|c|}
\hline Group & Model & TBA & $P$ & CVC \\
\hline \multicolumn{5}{|c|}{ HPV16 negative } \\
\hline \multirow[t]{4}{*}{ CIN1 } & A1 & 0.4763 & 0.9453 & $6 / 10$ \\
\hline & $\mathrm{A} 1 / \mathrm{A} 3$ & 0.6058 & 0.0510 & $10 / 10$ \\
\hline & $\mathrm{A} 1 / \mathrm{A} 3 / \mathrm{A} 4$ & 0.5457 & 0.1719 & $7 / 10$ \\
\hline & $\mathrm{A} 1 / \mathrm{A} 2 / \mathrm{A} 3 / \mathrm{A} 4$ & 0.5570 & 0.0547 & $10 / 10$ \\
\hline \multirow{4}{*}{ CIN2/3 } & A4 & 0.5926 & 0.1719 & $7 / 10$ \\
\hline & $\mathrm{A} 3 / \mathrm{A} 4$ & 0.6266 & 0.0547 & $8 / 10$ \\
\hline & A2/A3/A4 & 0.5950 & 0.0107 & $10 / 10$ \\
\hline & $\mathrm{A} 1 / \mathrm{A} 2 / \mathrm{A} 3 / \mathrm{A} 4 *$ & 0.6394 & 0.0107 & $10 / 10$ \\
\hline \multicolumn{5}{|c|}{ HPV16 positive } \\
\hline \multirow[t]{7}{*}{ CIN1 } & B1 & 0.4499 & 0.9893 & $5 / 10$ \\
\hline & $\mathrm{B} 1 / \mathrm{B} 4$ & 0.5180 & 0.0547 & $7 / 10$ \\
\hline & $\mathrm{B} 1 / \mathrm{B} 4 / \mathrm{B} 6 *$ & 0.5832 & 0.0107 & $10 / 10$ \\
\hline & B2/B3/B5/B7 & 0.5110 & 0.3770 & $3 / 10$ \\
\hline & $\mathrm{B} 2 / \mathrm{B} 3 / \mathrm{B} 4 / \mathrm{B} 5 / \mathrm{B} 7$ & 0.5132 & 0.3770 & $7 / 10$ \\
\hline & B2/B3/B4/B5/B6/B7 & 0.5496 & 0.3770 & $5 / 10$ \\
\hline & $\mathrm{B} 1 / \mathrm{B} 2 / \mathrm{B} 3 / \mathrm{B} 4 / \mathrm{B} 5 / \mathrm{B} 6 / \mathrm{B} 7$ & 0.5521 & 0.3770 & $10 / 10$ \\
\hline \multirow[t]{7}{*}{ CIN2/3 } & B6 & 0.6284 & 0.0107 & $10 / 10$ \\
\hline & B4/B6 & 0.6266 & 0.0547 & $8 / 10$ \\
\hline & B3/B6/B7 & 0.5547 & 0.1719 & $4 / 10$ \\
\hline & $\mathrm{B} 1 / \mathrm{B} 3 / \mathrm{B} 6 / \mathrm{B} 7$ & 0.5742 & 0.1719 & $4 / 10$ \\
\hline & B1/B3/B4/B6/B7 & 0.6333 & 0.0547 & $8 / 10$ \\
\hline & B1/B2/B3/B4/B6/B7* & 0.6394 & 0.0107 & $10 / 10$ \\
\hline & $\mathrm{B} 1 / \mathrm{B} 2 / \mathrm{B} 3 / \mathrm{B} 4 / \mathrm{B} 5 / \mathrm{B} 6 / \mathrm{B} 7$ & 0.6009 & 0.0107 & $10 / 10$ \\
\hline
\end{tabular}

In recent years, the combined detection of bacterial enzymes, such as, $\beta$-glucuronidase, coagulase, neuraminidase and leukocyte esterase, has been applied widely to evaluate the vaginal micro-ecology. Neuraminidase is closely related to Gardnerella infection [22]. Gardnerella could utilize the complement regulatory molecule CD59 to activate the epithelial p38-mitogen-activated protein kinase pathway in human epithelial cells, leading to cell death, Lactobacillus reduction and $\mathrm{PH}$ value elevation [23]. High expression of neuraminidase NEU3 in cancer cells leads to protection against programmed cell death, while in contrast, decreased NEU3 induces apoptosis, implying a critical role of NEU3 in the survival of cancer cells [24]. These studies indicated that vaginal neuraminidase may be a potential target for cervical cancer diagnosis and therapy. The results in our study showed that neuraminidase increased with the severity of CIN, suggesting that neuraminidase could be used as a potential biomarker in cervical lesions screening.

$\beta$-glucuronidase has been found to be associated with Escherichia coli [25]. Microbiome communities with abundant $L$. crispatus likely contribute to prevent Escherichia coli colonization and inhibit Escherichia coli activity in vagina [26]. $\beta$-glucuronidase may promote virulence by destroying the protective mucosa barrier, 
thus increasing susceptibility to HPV [15]. Therefore, $\beta$-glucuronidase has an important warning role in CIN progression.

Enterococci and Staphylococcus aureus in the vagina produce coagulase [26]. Enterococcus can produce volgamycin, which effectively inhibit the growth of spoilage organism, however, the coagulase produced by Staphylococcus aureus will deposit fibrin on the surface of the cells, inhibiting the phagocytosis of phagocytic cells [27]. Seidi et al [28] took advantage of the unique coagulation properties of Staphylococcus coagulase and genetically engineered it to generate a new fusion protein with novel anti-cancer properties. Our study showed that abnormal rate of coagulase changes along cervical lesions progress. The coagulase alteration which reflects ratio of Enterococcus to Staphylococcus aureus may provide meaningful clues to the association between vaginal bacterial and CIN.

Vaginal microbial diversity could reduce ability of the immune system to clear HPV [29, 30]. Some studies also reported that women with high vaginal microbial diversity were most likely to have persistent HPV infection [31, 32] and CIN [33]. In this study, we explored the associations between vaginal micro-environment factors and CIN in different HPV16 infection states. We found that the abnormal rates and risks of $\mathrm{H}_{2} \mathrm{O}_{2}$, cleanness, $\beta$-glucuronidase, neuraminidase were higher in CIN1 and CIN2/3 in HPV16 positive group. Hence, to detect vaginal micro-environment factors would be of great significance to prevent the progress of CIN in HPV16 positive women. Anita Mitra et al [34] identified Garderella and $L$. iners as the most high-risk combination for the development of CIN with an odds ratio of 34.1 in HR-HPV positive women compared to HR-HPV negative women. We also found that women with both vaginal micro-environment factors abnormality and HPV16 positive had a significantly higher risk for developing CIN. It was suggested that there might be synergistic effect between vaginal micro-environment factors abnormality and HPV16 infection in the progression of CIN.

A recent study demonstrated that Gardnerella, Atopobium, Prevotella, Sneathia were significantly enriched, whereas Lactobacillus spp. was underrepresented in cervical cancer group as well as in CIN group [12]. However, the interaction of multiple vaginal micro-environment factors that secrete these pathogens was not defined on the occurrence of CIN. Our results from GMDR analysis showed the synergistic effect between abnormities of vagina cleanness, $\mathrm{H}_{2} \mathrm{O}_{2}, \quad \beta$-glucuronidase and neuraminidase played an important role on CIN, and the role would be strengthened in women with HPV16 infection added with abnormities of $\mathrm{PH}$ and leukocyte esterase on CIN2/3. Lactic acid preferentially lyses bacteria other than Lactobacillus species $[35,36]$ and causes bacterial cell death by acidifying the cytosol, disrupting intracellular function [37], increasing the permeability of the cell membrane to $\mathrm{H}_{2} \mathrm{O}_{2}$, diacetyl et al. Gardnerella secretes neuraminidase that degrades vaginal mucus by cleaving sialic acid from the glycoproteins, increasing the risk of cervical disease [37]. A synergistic effect between Gardnerella and Prevotella was found in BV women [38]. In conclusion, our results suggested that vaginal micro-environment disorder could increase the risk of CIN, especially, the abnormality of $\mathrm{H}_{2} \mathrm{O}_{2}$, cleanness, $\beta$-glucuronidase and neuraminidase was of great significance to CIN regardless of HPV16 infection. There was interaction effect with abnormities of vagina cleanness, $\beta$-glucuronidase and neuraminidase on CIN regardless of HPV16 infection, particularly, with more vaginal micro-environment factors participating interaction effect in HPV16 positive group than HPV16 negative group. Although our study can't prove the causal association, we have found some valuable clues. Certainly, prospective cohort studies and experiment studies will be needed to provide powerful evidence in our future study.

\section{Acknowledgment}

We gratefully acknowledge the contribution of our coworkers involved in conducting the study and writing this article. We thank all the study participants, as well as the investigators and local healthcare workers from the Jiexiu Family Planning/Women and Children Health Service Center, for their help with the study. This study was financially supported by National Natural Science Foundation of China (81872705, 81273157, 81473060), National Health and Family Planning Commission of China (201402010) and Global Health Catalyzer Research Fund (2017).

\section{Competing Interests}

The authors have declared that no competing interest exists.

\section{References}

1. Bray F, Ferlay J, Soerjomataram I, Siegel RL, Torre LA, Jemal A. Global Cancer Statistics 2018: GLOBOCAN Estimates of Incidence and Mortality Worldwide for 36 Cancers in 185 Countries. CA Cancer J Clin. 2018; 68:394-424.

2. Wang HL, Xi L, Yang X, Xu N. Association of MBL2 exon1 polymorphisms with high-riskhuman papillomavirus infection and cervical cancers: a meta-analysis. Arch Gynecol Obstet. 2016; 294:1109-1116.

3. Senapati R, Nayak B, Kar SK, Dwibedi B. HPV Genotypes distribution in Indian women with and without cervical carcinoma: Implication for HPV vaccination program in Odisha, Eastern India. BMC Infect Dis. 2017; 17:30-40.

4. Shukla S, Mahata S, Shishodia G, Pandey A, Tyagi A, Vishnoi K, Basir SF, Das BC, Bharti AC. Functional Regulatory Role of STAT3 in HPV16-Mediated Cervical Carcinigenesis. Plos One. 2013; 8: e67849. 
5. Myers ER, McCrory DC, Nanda K, Bastian L, Matchar DB. Mathematical model for the natural history of human papillomavirus infection and cervical carcinogenesis. Am J Epidemiol. 2000; 151:1158-1171.

6. Moscicki AB. Impact of HPV infection in adolescent population. J Adolesc Health. 2005; 3: S3-S9.

7. Wang W, Li X, Yao X, Cheng X, Zhu Y. The characteristics analysis of intestinal microecology on cerebral infarction patients and its correlation with apolipoprotein E. Medicine (Baltimore). 2018,97(41): e12805.

8. Pattananandecha $\mathrm{T}$, Sirilun $\mathrm{S}$, Duangjitcharoen $\mathrm{Y}$, Sivamaruthi BS, Suwannalert P, Peerajan S, Chaiyasut C. Hydrolysed inulin alleviates the azoxymethane-induced preneoplastic aberrant crypt foci by altering selected intestinal microbiota in Sprague-Dawley rats. Pharm Biol. 2016, 54(9): 1596-1605.

9. Stringer AM, Logan RM. The role of oral flora in the development of chemotherapy-induced oral mucositis. J Oral Pathol Med. 2015, 44(2):81-87.

10. Chen L, Liu G, Dong HY, Liu CH. Study on clinical application of vaginitis rapid diagnostic kit. Chinese Sex science. 2016, 25(1):64-66.

11. Shi XY, Wang XJ, Wang Z, Chen Y. The application value of bacterial preenzyme in vagina micro-ecological evaluation. Zhejiang clinical medicine. 2015,(7):1183-1184.

12. Clarke MA, Rodriguez AC, Gage JC, Herrero R, Hildesheim A, Wacholder S, Burk R, Schiffman M. A large population-based study of age-related associations between vaginal $\mathrm{PH}$ and human papillomavirus infection. BMC Infect Dis. 2012; 12: 33-42

13. Castelão C, Silva APD, Matos A, Inácio Â, Bicho M, Rui M, Bicho MC. Association of myeloperoxidase polymorphism (G463A) with cervix cancer[J]. Molecular and Cellular Biochemistry. 2015, 404 (1):1-4.

14. Ravel J, Gajer P, Abdo Z, Schneider GM, Koenig SS, Mcculle SL, Karlebach S, Gorle R, Russell J, Tacket CO. Vaginal microbiome of reproductive-age women[J]. Proc Natl Acad Sci USA. 2011,108 Suppl 1(108 Suppl 1):4680-4687.

15. Wang ZL, Fu LY, Xiong ZA, Oin $\mathrm{O}$ Yu TH, Wu YT, Hua YY, Zhang YH Diagnosis and microecological characteristics of aerobic vaginitis in outpatients based on preformed enzymes [J]. Taiwanese Journal of Obstetrics \& Gynecology. 2016,55(1):40-44.

16. Ferreira CST, Marconi C, Gonçalves APO, Rudge MVC, Silva MGD, Ferreira CST, Marconi C. Bacterial vaginosis in pregnant adolescents: proinflammatory cytokine and bacterial sialidase profile. Cross-sectional study[J]. Sao Paulo medical journal. 2015, 133(6):465-470.

17. Mardh P , Niklasson O, Bekassy Z, Skude L. Leukocyte Esterase Activity in Vaginal Fluid of Pregnant and Non-Pregnant Women With Vaginitis/Vaginosis and in Controls[J]. Infectious Diseases in Obstetrics and Gynecology. 2003, 11(1):19-26.

18. YingWu Y, YuSan W. National guide to clinical lactobacillus procedures. Nan Jing: Southeast University Press. (Chinese). 2006.

19. Martin DH. The microbiota of the vagina and its influence on women's health and disease. Am J Med Sci. 2012; 343:2-9.

20. Petrova MI, Lievens E, Malik S, Imholz N, Lebeer S. 2015. Lactobacillus species as biomarkers and agents that can promote various aspects of vaginal health. Front Physio. 2015; 6:81-98

21. Klomp JM, Boon ME, Van Haaften M, Heintz AP. Cytologically diagnosed Gardnerella vaginalis, infection and cervical (pre) neoplasia as established in population-based cervical screening. Am J Obstet Gynecol. 2008; 199:480.e1-e5.

22. Briselden AM, Moncla BJ, Stevens CE, Hillier SL. Dialidases (neuraminidases) in bacterial vaginosis and bacterial vaginosis-associated microflora. J Clin Microbiol. 1992; 30:663-666.

23. Gelber SE, Aguilar JL, Lewis KL, Ratner AJ. Functional and phylogenetic characterization of Vaginolysin, the human-specific cytolysin from Gardnerella vaginalis. J Bacteriol. 2008; 190:3896-3903.

24. Paolini L, Orizio F, Busatto S, Radeghieri A, Bresciani R, Bergese P, Monti E. Exosomes secreted by HeLa cells shuttle on their surface the plasma membrane-associated sialidase NEU3. Biochemistry. 2017; 56:6401-6408.

25. Ghartey JP, Smith BC, Chen Z, Buckley N, Lo Y, Ratner AJ, Herold BC, Burk $\mathrm{RD}$. Lactobacillus crispatus dominant vaginal microbiome is associated with inhibitory activity of female genital tract secretions against Escherichia coli. Plos One. 2014; 9:e96659.

26. Chao Yang $Z$, Dong Fei C. A new method for rapid diagnosis of aerobic bacteria vaginitis. Chinese Journal of Microecology. 2011; 23:559-560.

27. Seidi K, Jahanban-Esfahlan R, Monhemi H, Zare P, Minofar B, Daei Farshchi Adli A, Farajzadeh D, Behzadi R, Mesgari Abbasi M, Neubauer HA, Moriggl $\mathrm{R}$, Zarghami N, Javaheri T. NGR (Asn-Gly-Arg)-targeted delivery of coagulase to tumor vasculature arrests cancer cell growth. Oncogene. 2018; 37:3967-3980.

28. Lee JE, Lee S, Lee H, Song YM, Lee K, Han MJ, Sung J, Ko G. Association of the vaginal microbiota with human papillomavirus infection in a Korean twin cohort. PLoS One. 2013; 8:e63514.

29. Ma B, Forney LJ, Ravel J. Vaginal microbiome: rethinking health and disease. Annual Rev Microbiol. 2012; 66: 371-389.

30. Brotman RM, Shardell MD, Gajer P, Tracy JK, Zenilman JM, Ravel J, Gravitt PE. Interplay between the Temporal Dynamics of the Vaginal Microbiota and Human Papillomavirus Detection. J Infect Dis. 2014; 210:1723-1733.

31. Mitra A, MacIntyre DA, Lee YS, Smith A, Marchesi JR, Lehne B, Bhatia R, Lyons D, Paraskevaidis E, Li JV, Holmes E, Nicholson JK, Bennett PR, Kyrgiou M. Cervical intraepithelial neoplasia disease progression is associated with increased vaginal microbiome diversity. Sci Rep. 2015; 5:16865.

32. Łaniewski P, Barnes D, Goulder A, Cui H, Roe DJ, Chase DM, Herbst-Kralovetz MM. Linking cervicovaginal immune signatures, HPV and microbiota composition in cervical carcinogenesis in non-Hispanic and Hispanic women. Sci Rep. 2018; 8:7593.

33. Dasari S, Rajendra W, Valluru L. Evaluation of microbial enzymes in normal and abnormal cervicovaginal fluids of cervical dysplasia: a case control study. Biomed Res Int. 2014; 1-6.

34. Mitra A, Macintyre DA, Marchesi JR, Lee YS, Bennett PR, Kyrgiou M. The vaginal microbiota, human papillomavirus infection and cervical intraepithelial neoplasia: what do we know and where are we going next? Microbiome. 2016; 4:58-73.

35. O'Hanlon DE, Moench TR, Cone RA. Vaginal PH and microbicidal lacticacid when lactobacilli dominate the microbiota. PLoS One. 2013; 8:e80074.

36. O'Hanlon DE, Moench TR, Cone RA. In vaginal fluid, bacteria associated with bacterial vaginosis can be suppressed with lactic acid but not hydrogen peroxide. BMC Infect Dis. 2011; 11:200-208.

37. Amabebe E, Anumba Doc. The Vaginal Microenvironment: The Physiologic Role of Lactobacilli. Front Med (Lausanne). 2018; 5:181-192.

38. Datcu R, Gesink D, Mulvad G, Montgomery-Andersen R, Rink E, Koch A, Ahrens P, Jensen JS. Vaginal microbiome in women from Greenland assessed by microscopy and quantitative PCR. BMC Infect Dis. 2013; 13:480-494. 